\title{
Ergonomic Risk Factors of Work Processes in the Semiconductor Industry in Peninsular Malaysia
}

\author{
Heng-Leng CHEE ${ }^{1 *}$, Krishna Gopal RAMPAL ${ }^{2}$ and Abherhame CHANDRASAKARAN ${ }^{3}$ \\ ${ }^{1}$ Asia Research Institute, National University of Singapore, AS7 Shaw Foundation Building Level 4, 5 Arts Link, \\ Singapore 117570 \\ ${ }^{2}$ Department of Community Health, Faculty of Medicine, Universiti Kebangsaan Malaysia, 56000 Cheras, Kuala \\ Lumpur, Malaysia \\ ${ }^{3}$ Department of Community Health, Faculty of Medicine and Health Sciences, Universiti Putra Malaysia, 43400 \\ UPM Serdang, Selangor, Malaysia
}

Received May 29, 2003 and accepted March 24, 2004

\begin{abstract}
A cross-sectional survey of semiconductor factories was conducted to identify the ergonomic risk factors in the work processes, the prevalence of body pain among workers, and the relationship between body pain and work processes. A total of 906 women semiconductor workers took part in the study. In wafer preparation and polishing, a combination of lifting weights and prolonged standing might have led to high pain prevalences in the low back $(35.0 \%$ wafer preparation, $41.7 \%$ wafer polishing) and lower limbs (90.0\% wafer preparation, $66.7 \%$ wafer polishing). Semiconductor front of line workers, who mostly walked around to operate machines in clean rooms, had the lowest prevalences of body pain. Semiconductor assembly middle of line workers, especially the molding workers, who did frequent lifting, had high pain prevalences in the neck/shoulders $(54.8 \%)$ and upper back (43.5\%). In the semiconductor assembly end of line work section, chip inspection workers who were exposed to prolonged sitting without back support had high prevalences of neck/shoulder $(62.2 \%)$ and upper back pain $(\mathbf{5 0 . 0 \%})$, while chip testing workers who had to climb steps to load units had a high prevalence of lower limb pain $(\mathbf{6 8 . 0 \%})$. Workers in the assembly of electronic components, carrying out repetitive tasks with hands and fingers, and standing in awkward postures had high pain prevalences in the neck/shoulders (61.5\%), arms (38.5\%), and hands/wrists $(30.8 \%)$.
\end{abstract}

Key words: Semiconductor industry, Women workers, Ergonomic risk factors

\section{Introduction}

The electronics industry spans a very diverse range of production processes with companies straddling many countries ${ }^{1}$. Overall, the foremost occupational hazards associated with this industry have primarily been from exposure to chemicals. Nevertheless, another work-related condition that has been identified is musculoskeletal disorders from ergonomic risk exposures. Most ergonomic studies in the electronics industry have been carried out in electronic

*To whom correspondence should be addressed. product assembly, rather than semiconductor assembly. Recent studies on musculoskeletal problems among electronics workers in developing countries range from one focussed specifically on carpal tunnel syndrome in an Egyptian electronics assembly factory ${ }^{2}$ to a general study of sociodemographic and occupational risk factors for musculoskeletal complaints among women in Tijuana Mexico $^{3}$. In Malaysia, studies on ergonomics task analysis has been carried out among workers in two factories, one producing electronic components and the other, audio electronic equipment ${ }^{4,5)}$; while in Singapore, studies have recorded aches and pains among workers in a disk drive factory $^{6}$ ) and wrist pain among workers at a factory 
manufacturing motors for refrigerators ${ }^{7}$.

Among the few ergonomic studies in the semiconductor industry is one that was carried out under the umbrella of the large-scale Semiconductor Health Study (SHS) that was sponsored by the semiconductor industry in the United States. The SHS focussed on reproductive health hazards of chemical exposure $^{8)}$, but it included a cross-sectional study of musculoskeletal problems among wafer fabrication and nonwafer fabrication workers ${ }^{9)}$. In Malaysia and Singapore, Lin studied the occupational health and safety of 903 women workers from five semiconductor factories in the mid $1980 \mathrm{~s}^{10)}$. Among the health problems reported in her study were musculo-skeletal problems, the major ones being back and shoulder ache as well as pain in hand and arm.

In Malaysia, the electronics industry is the leading industry in the manufacturing sector and one of the largest employers $^{11,12)}$. Within electronics, semiconductors is the biggest sector, accounting for more than a third of total electronics exports. The occupational health and safety of semiconductor workers is therefore an important research topic, and in 1998-2002, a government-funded study was carried out in the semiconductor industry on various aspects of occupational health and safety, including ergonomics. The study decided to focus exclusively on women workers, because they constitute more than $80 \%$ of the industry workforce. Findings from this study have identified work process to be an important factor that is related to body pain ${ }^{13)}$. This paper follows up on these previous findings with more in-depth analysis. In this paper, the objectives are to describe the ergonomic risks observed in the work processes, to identify the particular work processes that have high prevalences of body pain, and to use the qualitative observations to understand the prevalences of body pain.

\section{Methods}

The research design used in this study was a cross-sectional survey. A total of 24 semiconductor factories located in two geographical clusters were identified from the Malaysian Industrial Development Authority (MIDA) 31 ${ }^{\text {st }}$ Aug 1998 list, and invited to participate in the survey. However, only 18 agreed to participate, resulting in a $75 \%$ participation rate. Data collection was from July 1999 to March 2000. The researchers visited each factory where they were first briefed by human resource and safety and health personnel on work processes, hazards, and health and safety policies; following which they were taken on a walk-through survey of the plant.

For the workers' survey, the management of each factory was asked to provide a $10 \%$ sample of women workers who were Malaysian citizens, had worked for at least a year in the factory, and were direct production line operators below the supervisory level. A minimum of 30 workers were obtained from factories with fewer than 300 women workers, and a maximum of 200 from factories with more than 2,000 workers. The researchers requested that the selection should be random, and that each work process should be represented.

Workers were released from production in batches to participate in the study. The researchers first briefed the participants on the objectives of the study and emphasized to them that the information they give would be treated confidentially. A self-administered questionnaire in Malay was employed. Individual identification was not required in the questionnaire and workers were reassured that data would not be identifiable by specific factories.

The outcome measure was pain in the last one year, which was derived from respondents circling the sites where they experienced pain on a body map that had been modified from the Nordic Musculoskeletal Questionnaire ${ }^{14)}$. Differences in means were tested by the ANOVA, while association between variables were tested by chi-square. The binary logistic regression was used to calculate odds ratios for pain at each body site by work process, adjusted for age. Work duration was not included as a covariate in the logistic regression analysis due to its high correlation with age.

\section{Results}

\section{Factories and work processes}

The final number of women workers who took part in the workers' survey was 968 . In order to eliminate the confounding effects of pregnancy, however, only those who were not currently pregnant (906) were included in this paper. The respondents were from 18 factories, among which 15 were carrying out semiconductor assembly and three wafer fabrication. The wafer fabrication factories in Malaysia do not carry out the entire process of wafer fabrication, but only wafer polishing and the steps immediately prior and subsequent to it. Wafer preparation and polishing had respondents from two of the factories, while wafer inspection and packing had respondents from three factories (Table 1).

In the wafer fabrication factories, there was a distinct preference for employing women for the tasks of inspection and packing, while male employees were preferred for the other tasks. As only women workers were selected for this study, there would be an under-representation of the tasks in wafer preparation and wafer polishing, relative to wafer inspection and packaging. Overall, women made up $45 \%$ 
Table 1. Distribution of respondents, mean age and mean working duration by work section and work process

\begin{tabular}{|c|c|c|c|c|}
\hline \multirow{2}{*}{$\begin{array}{l}\text { Work section and work process } \\
\text { (no. of companies) }\end{array}$} & \multicolumn{2}{|c|}{ Distribution of respondents } & \multirow{2}{*}{$\begin{array}{c}\text { Mean age }( \pm \mathrm{SD}) \\
(\mathrm{yr})\end{array}$} & \multirow{2}{*}{$\begin{array}{c}\text { Mean working } \\
\text { duration }( \pm \mathrm{SD})(\mathrm{yr})\end{array}$} \\
\hline & No. & $\%$ & & \\
\hline Wafer fabrication & 86 & 9.5 & $31.4( \pm 8.0)$ & $9.9( \pm 7.8)$ \\
\hline Wafer preparation (2) & 20 & 2.2 & $38.6( \pm 7.3)$ & $17.1( \pm 6.6)$ \\
\hline Wafer polishing (2) & 12 & 1.3 & $34.4( \pm 10.0)$ & $14.2( \pm 8.9)$ \\
\hline Wafer inspection and packing (3) & 54 & 6.0 & $28.0( \pm 5.4)$ & $6.3( \pm 5.5)$ \\
\hline Semiconductor assembly & 774 & 85.4 & & \\
\hline Front of line (FOL) & $(172)$ & $(19.0)$ & $30.6( \pm 7.9)$ & $10.0( \pm 8.2)$ \\
\hline Die preparation (10) & 64 & 7.1 & $31.1( \pm 7.6)$ & $10.7( \pm 8.6)$ \\
\hline Die attach (9) & 55 & 6.1 & $31.1( \pm 8.6)$ & $10.9( \pm 8.6)$ \\
\hline Wire bonding (9) & 53 & 5.8 & $29.5( \pm 7.6)$ & $8.2( \pm 7.0)$ \\
\hline Middle of line (MOL) & $(168)$ & $(18.5)$ & $30.0( \pm 7.7)$ & $9.1( \pm 7.5)$ \\
\hline Molding (8) & 59 & 6.5 & $31.4( \pm 7.8)$ & $10.2( \pm 7.9)$ \\
\hline Forming/ trimming (8) & 35 & 3.9 & $28.0( \pm 7.6)$ & $7.3( \pm 7.2)$ \\
\hline Plating/ soldering (10) & 58 & 6.4 & $30.1( \pm 7.4)$ & $9.3( \pm 7.0)$ \\
\hline Dejunk/ deflash (5) & 16 & 1.8 & $28.9( \pm 8.5)$ & $7.5( \pm 7.5)$ \\
\hline End of line (EOL) & $(434)$ & $(47.9)$ & $30.7( \pm 8.4)$ & $8.6( \pm 7.5)$ \\
\hline Die marking and curing (11) & 58 & 6.4 & $30.3( \pm 8.0)$ & $8.6( \pm 6.7)$ \\
\hline Chip testing (9) & 122 & 13.5 & $31.7( \pm 8.3)$ & $10.9( \pm 7.9)$ \\
\hline Chip burn-in (8) & 73 & 8.1 & $30.5( \pm 9.1)$ & $5.1( \pm 4.4)$ \\
\hline Chip inspection (11) & 98 & 10.8 & $29.9( \pm 8.0)$ & $7.9( \pm 7.5)$ \\
\hline Chip packing (10) & 83 & 9.1 & $30.5( \pm 8.5)$ & $9.2( \pm 8.4)$ \\
\hline Parts assembly & 46 & 5.1 & $30.9( \pm 7.8)$ & $7.8( \pm 6.1)$ \\
\hline Assembly (3) & 26 & 2.9 & $30.3( \pm 8.0)$ & $7.2( \pm 6.8)$ \\
\hline Testing, marking, packing (3) & 20 & 2.2 & $31.7( \pm 7.7)$ & $8.7( \pm 5.0)$ \\
\hline
\end{tabular}

of the total number of direct production workers in the wafer fabrication factories, and $89 \%$ in the semiconductor factories, where they were by far the majority in every production process.

The semiconductor assembly factories in the study, when considered together, had all the processes from the front of line (FOL) work section, through the middle of line (MOL) to the end of line (EOL). Some of the factories had contracted out parts of the production process, while two specialized in burn-in testing. Parts assembly, primarily manual assembly of component parts, diodes and other electronic components, was carried out in three of the semiconductor assembly factories.

There were respondents from all work processes present in all the factories. However, the researchers were not able to obtain the breakdown numbers of the workforce by work process in each factory, and therefore the proportions represented could not be calculated. The majority of respondents were in semiconductor assembly $(85.4 \%)$, with most from the EOL $(47.9 \%)$ where testing $(13.5 \%)$ and inspection $(10.8 \%)$ predominated. In wafer fabrication, inspection and packing workers were the largest group (6.0\%).
Median age and work duration were $30.0 \mathrm{yr}$ and $6.0 \mathrm{yr}$ respectively. Neither were significantly different by work section ( $p>0.05$ ) (Table 1). Nevertheless, when disaggregated by the 17 work processes, workers in wafer preparation were the oldest (38.6 yr) and had worked the longest (17.1 yr), followed by workers in wafer polishing (34.4 $\mathrm{yr}$ old, 14.2 yr work duration). Workers in burn-in had worked the shortest time (5.1 yr), but the youngest ( $28.0 \mathrm{yr}$ ) were workers in wafer inspection and packing, and forming/ trimming.

\section{Prevalence of body pain}

The overall prevalence of pain at any part of the body was $80.5 \%$. Body pain at each of the six body sites was significantly associated with work section $(\mathrm{p}<0.05)$ (Table $2)$. Work process was only significantly associated with arm pain $(\mathrm{p}<0.01)$ and lower limb pain $(\mathrm{p}<0.001)$. The work processes with the highest pain prevalences (Table 2) also had the highest odds ratios (Table 3 ). The odds ratios have the advantage of being adjusted for age, but many of them had extremely wide $95 \%$ confidence intervals $(>20)$, indicating imprecise measurement. It is useful, therefore, to use both pain prevalences as well as odds ratios to indicate 
Table 2. Percentage distribution of workers experiencing pain in various parts of the body by work section and work process

\begin{tabular}{|c|c|c|c|c|c|c|}
\hline & \multicolumn{6}{|c|}{ Percentage experiencing pain } \\
\hline & Neck/shoulders & Arms & Hands/wrists & Upper back & Low back & Lower limbs \\
\hline Wafer fabrication $(n=86)$ & 47.7 & 16.3 & 15.1 & 31.4 & 32.6 & 64.0 \\
\hline Wafer preparation $(\mathrm{n}=20)$ & 45.0 & 10.0 & 20.0 & 40.0 & 35.0 & 90.0 \\
\hline Wafer polishing $(\mathrm{n}=12)$ & 50.0 & 8.3 & 8.3 & 16.7 & 41.7 & 66.7 \\
\hline Wafer inspection, packing $(\mathrm{n}=54)$ & 48.1 & 20.4 & 14.8 & 31.5 & 29.6 & 53.7 \\
\hline$S A F O L(n=172)$ & 40.1 & 23.3 & 13.4 & 33.1 & 18.6 & 50.6 \\
\hline Die preparation $(n=64)$ & 32.8 & 26.6 & 14.1 & 34.4 & 20.3 & 43.8 \\
\hline Die attach $(n=55)$ & 45.5 & 10.9 & 12.7 & 25.5 & 18.2 & 58.2 \\
\hline Wire bonding $(\mathrm{n}=53)$ & 43.4 & 32.1 & 13.2 & 39.6 & 17.0 & 50.9 \\
\hline$S A M O L(n=168)$ & 54.8 & 25.6 & 19.6 & 43.5 & 22.0 & 54.2 \\
\hline Molding $(\mathrm{n}=59)$ & 61.0 & 37.3 & 23.7 & 45.8 & 20.3 & 59.3 \\
\hline Forming/ trimming $(\mathrm{n}=35)$ & 54.3 & 20.0 & 17.1 & 45.7 & 28.6 & 51.4 \\
\hline Plating/ soldering $(\mathrm{n}=58)$ & 48.3 & 20.7 & 20.7 & 37.9 & 20.7 & 58.6 \\
\hline Dejunk/ deflash $(n=16)$ & 56.3 & 12.5 & 6.3 & 50.0 & 18.8 & 25.0 \\
\hline$S A E O L(n=434)$ & 55.3 & 31.1 & 24.2 & 44.0 & 27.0 & 50.9 \\
\hline Die marking and curing $(\mathrm{n}=58)$ & 53.4 & 39.7 & 24.1 & 34.5 & 20.7 & 56.9 \\
\hline Chip testing ( $\mathrm{n}=122)$ & 54.1 & 32.8 & 27.9 & 48.4 & 28.7 & 68.0 \\
\hline Chip burn-in ( $\mathrm{n}=73)$ & 52.1 & 31.5 & 28.8 & 37.0 & 31.5 & 37.0 \\
\hline Chip inspection $(\mathrm{n}=98)$ & 62.2 & 31.6 & 20.4 & 50.0 & 22.4 & 36.7 \\
\hline Chip packing $(\mathrm{n}=83)$ & 53.0 & 21.7 & 19.3 & 43.4 & 30.1 & 50.6 \\
\hline Parts assembly $(n=46)$ & 50.0 & 30.4 & 21.7 & 34.8 & 13.0 & 37.0 \\
\hline Assembly $(\mathrm{n}=26)$ & 61.5 & 38.5 & 30.8 & 38.5 & 11.5 & 38.5 \\
\hline Testing, marking, packing $(\mathrm{n}=20)$ & 35.0 & 20.0 & 10.0 & 30.0 & 15.0 & 35.0 \\
\hline All work processes $(n=906)$ & 51.3 & 27.2 & 20.3 & 40.2 & 24.3 & 52.0 \\
\hline$\chi^{2}$ for work section $(\mathrm{df}=4)$ & 12.7 & 10.3 & 10.7 & 10.3 & 11.5 & 9.8 \\
\hline p-value & $0.013 *$ & $0.035^{*}$ & $0.030^{*}$ & $0.036^{*}$ & $0.021 *$ & $0.045^{*}$ \\
\hline$\chi^{2}$ for work process $(\mathrm{df}=16)$ & 22.6 & 33.0 & 21.0 & 22.0 & 17.5 & 55.4 \\
\hline p-value & 0.124 & $0.007 * *$ & 0.178 & 0.144 & 0.354 & $0.000 * * *$ \\
\hline
\end{tabular}

SA: Semiconductor assembly, FOL: Front of line, MOL: middle of line, EOL: end of line. ${ }^{*}: \mathrm{p}<0.05, * *$ : $\mathrm{p}<0.01, * * *$ : $\mathrm{p}<0.001$.

increased risk.

Neck/shoulder pain was highest among the MOL (54.8\%) and EOL workers $(55.3 \%)$, specifically in molding $(61.0 \%)$, and chip inspection $(62.2 \%)$; but also in assembly $(61.5 \%)$ (Table 2). The odds ratios were significantly raised to 3.3 for both molding (95\% CI=1.6-6.9) and chip inspection (95\% $\mathrm{CI}=1.7-6.4)$, and 3.2 for assembly (95\% CI=1.3-8.4) (Table 3). The odds ratios were also significantly raised for all the other processes in EOL.

In general, arm pain was low. Among the different work processes, however, the prevalence was relatively high for die marking and curing (39.7\%), assembly (38.5\%), and molding (37.3\%). The prevalence of hand/wrist pain was lower than expected (20.3\%), but relatively high among EOL workers $(24.2 \%)$, especially in burn in $(28.8 \%)$ and chip testing $(27.9 \%)$, as well as among the assembly workers $(30.8 \%)$. These processes with the highest prevalences corresponded with the highest odds ratios, even though the odds ratios were not significant.

The prevalence of upper back pain was highest in EOL (44.0\%) and MOL (43.5\%) work sections. The workers most affected were those in chip inspection $(50.0 \%)$ and chip testing (48.4\%) in EOL, and in MOL, those in dejunk/ deflash (50.0\%), forming/trimming (45.7\%), and molding $(45.8 \%)$. Low back pain was generally less prevalent. However, it was relatively higher in wafer preparation (35.0\%), wafer polishing (41.7\%), chip burn-in (31.5\%) and chip packing $(30.1 \%)$. Again, the processes with the highest prevalences were also those with the highest odds ratios, but the levels were not statistically significant.

Lower limb pain was highest in wafer preparation $(90.0 \%)$, wafer polishing $(66.7 \%)$, and chip testing $(68.0 \%)$. Wafer preparation workers faced 22 times significantly higher odds of lower limb pain, but this measurement was imprecise 
Table 3. Odds ratios for pain at specific body sites by work process (adjusted for age)

\begin{tabular}{|c|c|c|c|c|c|c|}
\hline & \multicolumn{6}{|c|}{ Odds ratio $^{1}(95 \% \mathrm{CI})$ for pain in the last one year at } \\
\hline & Neck/shoulders & Arms & Hands/wrists & Upper back & Low back & Lower limbs \\
\hline \multicolumn{7}{|l|}{ Wafer fabrication $(n=86)$} \\
\hline Wafer preparation $(\mathrm{n}=20)$ & $\begin{array}{c}2.1 \\
(0.7-5.8)\end{array}$ & $\begin{array}{c}1.3 \\
(0.1-16)\end{array}$ & $\begin{array}{c}4.3 \\
(0.4-43)\end{array}$ & $\begin{array}{c}3.8 \\
(0.7-23)\end{array}$ & $\begin{array}{c}4.0 \\
(0.9-18)\end{array}$ & $\begin{array}{c}22 \\
(3.5-142)^{*}\end{array}$ \\
\hline Wafer polishing $(n=12)$ & $\begin{array}{c}2.3 \\
(0.6-7.9)\end{array}$ & 1.0 & $\begin{array}{c}1.5 \\
(0.1-26)\end{array}$ & 1.0 & $\begin{array}{c}5.4 \\
(1.0-28)\end{array}$ & $\begin{array}{c}5.4 \\
(1.0-28)\end{array}$ \\
\hline Wafer inspection, packing $(\mathrm{n}=54)$ & $\begin{array}{c}1.8 \\
(0.8-3.7)\end{array}$ & $\begin{array}{c}2.7 \\
(0.3-23)\end{array}$ & $\begin{array}{c}2.6 \\
(0.3-22)\end{array}$ & $\begin{array}{c}2.0 \\
(0.4-10)\end{array}$ & $\begin{array}{c}3.3 \\
(0.9-12)\end{array}$ & $\begin{array}{c}3.6 \\
(1.0-13)\end{array}$ \\
\hline \multicolumn{7}{|l|}{$\operatorname{SAFOL}(n=172)$} \\
\hline Die preparation $(n=64)$ & 1.0 & $\begin{array}{c}3.9 \\
(0.5-32)\end{array}$ & $\begin{array}{c}2.5 \\
(0.3-22)\end{array}$ & $\begin{array}{c}2.4 \\
(0.5-12)\end{array}$ & $\begin{array}{c}1.9 \\
(0.5-7.5)\end{array}$ & $\begin{array}{c}2.2 \\
(0.6-7.7)\end{array}$ \\
\hline Die attach $(n=55)$ & $\begin{array}{c}1.7 \\
(0.8-3.6)\end{array}$ & $\begin{array}{c}1.3 \\
(0.1-12)\end{array}$ & $\begin{array}{c}2.3 \\
(0.3-20)\end{array}$ & $\begin{array}{c}1.6 \\
(0.3-8.1)\end{array}$ & $\begin{array}{c}1.7 \\
(0.4-6.8)\end{array}$ & $\begin{array}{c}4.0 \\
(1.1-14)^{*}\end{array}$ \\
\hline Wire bonding $(\mathrm{n}=53)$ & $\begin{array}{c}1.5 \\
(0.7-3.2)\end{array}$ & $\begin{array}{c}5.0 \\
(0.6-42)\end{array}$ & $\begin{array}{c}2.3 \\
(0.3-20)\end{array}$ & $\begin{array}{c}2.9 \\
(0.6-15)\end{array}$ & $\begin{array}{c}1.6 \\
(0.4-6.4)\end{array}$ & $\begin{array}{c}3.1 \\
(0.9-11)\end{array}$ \\
\hline \multicolumn{7}{|l|}{$S A M O L(n=168)$} \\
\hline Molding (n=59) & $\begin{array}{c}3.3 \\
(1.6-6.9)^{*}\end{array}$ & $\begin{array}{c}6.4 \\
(0.8-53)\end{array}$ & $\begin{array}{c}4.8 \\
(0.6-40)\end{array}$ & $\begin{array}{c}4.0 \\
(0.8-20)\end{array}$ & $\begin{array}{c}1.9 \\
(0.5-7.6)\end{array}$ & $\begin{array}{c}4.2 \\
(1.2-15)^{*}\end{array}$ \\
\hline Forming/ trimming $(\mathrm{n}=35)$ & $\begin{array}{c}2.3 \\
(1.0-5.3)\end{array}$ & $\begin{array}{c}2.6 \\
(0.3-24)\end{array}$ & $\begin{array}{c}3.1 \\
(0.3-28)\end{array}$ & $\begin{array}{c}3.6 \\
(0.7-19)\end{array}$ & $\begin{array}{c}3.1 \\
(0.8-13)\end{array}$ & $\begin{array}{c}3.3 \\
(0.9-12)\end{array}$ \\
\hline Plating/ soldering $(\mathrm{n}=58)$ & $\begin{array}{c}1.9 \\
(0.9-3.9)\end{array}$ & $\begin{array}{c}2.8 \\
(0.3-24)\end{array}$ & $\begin{array}{c}4.0 \\
(0.5-33)\end{array}$ & $\begin{array}{c}2.8 \\
(0.5-14)\end{array}$ & $\begin{array}{c}2.0 \\
(0.5-7.8)\end{array}$ & $\begin{array}{c}4.2 \\
(1.2-15)^{*}\end{array}$ \\
\hline Dejunk/ deflash $(n=16)$ & $\begin{array}{c}2.5 \\
(0.8-7.7)\end{array}$ & $\begin{array}{c}1.5 \\
(0.1-19)\end{array}$ & 1.0 & $\begin{array}{c}4.4 \\
(0.7-27)\end{array}$ & $\begin{array}{c}1.8 \\
(0.3-10)\end{array}$ & 1.0 \\
\hline \multicolumn{7}{|l|}{ SA EOL $(n=434)$} \\
\hline Die marking and curing $(\mathrm{n}=58)$ & $\begin{array}{c}2.3 \\
(1.1-4.9)^{*}\end{array}$ & $\begin{array}{c}7.0 \\
(0.8-58)\end{array}$ & $\begin{array}{c}4.9 \\
(0.6-40)\end{array}$ & $\begin{array}{c}2.4 \\
(0.5-12)\end{array}$ & $\begin{array}{c}2.0 \\
(0.5-7.8)\end{array}$ & $\begin{array}{c}3.9 \\
(1.1-14)^{*}\end{array}$ \\
\hline Chip testing $(\mathrm{n}=122)$ & $\begin{array}{c}2.5 \\
(1.3-4.7)^{*}\end{array}$ & $\begin{array}{c}5.3 \\
(0.7-42)\end{array}$ & $\begin{array}{c}6.0 \\
(0.8-48)\end{array}$ & $\begin{array}{c}4.4 \\
(0.9-21)\end{array}$ & $\begin{array}{c}3.1 \\
(0.9-11)\end{array}$ & $\begin{array}{c}6.1 \\
(1.8-20)^{*}\end{array}$ \\
\hline Chip burn-in (n=73) & $\begin{array}{c}2.2 \\
(1.1-4.4)^{*}\end{array}$ & $\begin{array}{c}4.9 \\
(0.6-40)\end{array}$ & $\begin{array}{c}6.2 \\
(0.8-50)\end{array}$ & $\begin{array}{c}2.7 \\
(0.5-13)\end{array}$ & $\begin{array}{c}3.5 \\
(1.0-13)\end{array}$ & $\begin{array}{c}1.7 \\
(0.5-5.8)\end{array}$ \\
\hline Chip inspection $(\mathrm{n}=98)$ & $\begin{array}{c}3.3 \\
(1.7-6.4)^{*}\end{array}$ & $\begin{array}{c}4.9 \\
(0.6-40)\end{array}$ & $\begin{array}{c}3.9 \\
(0.5-31)\end{array}$ & $\begin{array}{c}4.5 \\
(0.9-22)\end{array}$ & $\begin{array}{c}2.2 \\
(0.6-8.1)\end{array}$ & $\begin{array}{c}1.7 \\
(0.5-5.7)\end{array}$ \\
\hline Chip packing $(\mathrm{n}=83)$ & $\begin{array}{c}2.3 \\
(1.2-4.6)^{*}\end{array}$ & $\begin{array}{c}3.0 \\
(0.4-24)\end{array}$ & $\begin{array}{c}3.7 \\
(0.5-30)\end{array}$ & $\begin{array}{c}3.5 \\
(0.7-17)\end{array}$ & $\begin{array}{c}3.3 \\
(0.9-12)\end{array}$ & $\begin{array}{c}3 \\
(0.9-10)\end{array}$ \\
\hline \multicolumn{7}{|l|}{ Parts assembly $(n=46)$} \\
\hline Assembly $(\mathrm{n}=26)$ & $\begin{array}{c}3.2 \\
(1.3-8.4)^{*}\end{array}$ & $\begin{array}{c}6.7 \\
(0.7-60)\end{array}$ & $\begin{array}{c}6.8 \\
(0.8-61)\end{array}$ & $\begin{array}{c}2.8 \\
(0.5-16)\end{array}$ & 1.0 & $\begin{array}{c}1.8 \\
(0.5-7.3)\end{array}$ \\
\hline Testing, marking, packing $(\mathrm{n}=20)$ & $\begin{array}{c}1.1 \\
(0.4-3.2)\end{array}$ & $\begin{array}{c}2.7 \\
(0.3-27)\end{array}$ & $\begin{array}{c}1.7 \\
(0.1-21)\end{array}$ & $\begin{array}{c}2.0 \\
(0.3-12)\end{array}$ & $\begin{array}{c}1.3 \\
(0.2-7.5)\end{array}$ & $\begin{array}{c}1.5 \\
(0.4-6.6)\end{array}$ \\
\hline
\end{tabular}

SA: Semiconductor assembly, FOL: Front of line, MOL: middle of line, EOL: end of line. ${ }^{1}$ Odds ratios for pain at each body site were obtained by logistic regression analysis with work process and age (continuous variable) as covariates. *: Statistically significant.

(95\% CI=3.5-142). Odds ratios were also significantly higher for chip testing (OR 6.1, 95\% CI=1.8-20), die marking (OR $3.9,95 \% \mathrm{CI}=1.1-14)$, die attach (OR 4.0, 95\% CI=1.1-14), molding, and plating (both OR 4.2, 95\% CI=1.2-15).

\section{Observation of ergonomic risk factors}

The ergonomic risk factors of the various work processes are summarised in Table 4 . These are primarily based on observations during the walk-through survey in each of the factories, supplemented with the information given by factory personnel during the factory visit.

In the three wafer fabrication factories, activities such as lifting big and heavy ingots (weighing more than $30 \mathrm{~kg}$ ), lifting racks containing wafers, repetitive work, prolonged 
Table 4. Ergonomic risk factors by work process

\begin{tabular}{|c|c|c|}
\hline Work process & & Ergonomic risk factors \\
\hline \multicolumn{3}{|l|}{ Wafer fabrication } \\
\hline \multirow[t]{3}{*}{ Wafer preparation } & Ingot mounting & Lifting ingots $(>30 \mathrm{~kg})$ \\
\hline & Ingot slicing & Lifting racks containing wafers \\
\hline & Inspection & Repetitive work, awkward posture \\
\hline \multirow[t]{2}{*}{ Wafer polishing } & Mounting & Prolonged standing, lifting racks ( $>1 \mathrm{~kg}$ ), repetitive work tasks \\
\hline & Other processes & Prolonged standing \\
\hline \multirow[t]{2}{*}{ Inspection \& packing } & Wafer inspection & Repetitive work, awkward posture, prolonged sitting \\
\hline & Wafer packing & Repetitive work, awkward posture \\
\hline \multicolumn{3}{|l|}{ Semiconductor assembly } \\
\hline \multirow[t]{3}{*}{ Front of line (FOL) } & Inspection & $\begin{array}{l}\text { Prolonged sitting, footrest available but no back support (stool). Shoulders } \\
\text { lifted (raised) because table too high. }\end{array}$ \\
\hline & Die attach & $\begin{array}{l}\text { Lifting racks about } 3 \mathrm{~kg} \text { ( } 6 \text { to } 8 \text { times per hour) and the operator had to operate } \\
\text { several machines that were } 3 \mathrm{~m} \text { apart from each other. }\end{array}$ \\
\hline & Oven cure & $\begin{array}{l}\text { The height of the oven was too high, therefore the worker had to stand on a } \\
\text { stool to load and unload the trays that weighed } 1 \text { to } 2 \mathrm{~kg} \text {. }\end{array}$ \\
\hline Middle of line (MOL) & Molding & $\begin{array}{l}\text { With the conventional machine, the molding metal frame weighed } 15-20 \mathrm{~kg} \text {. } \\
\text { New machines used small frames of } 4 \mathrm{~kg} \text { per set. }\end{array}$ \\
\hline \multirow[t]{3}{*}{ End of line (EOL) } & Chip testing & Worker had to climb three steps up to load the strips of chips onto the carrier. \\
\hline & Burn-in testing & $\begin{array}{l}\text { A worker who loaded the chips manually onto the burn-in board moved her } \\
\text { hand repetitively as she inserted } 1,500 \text { units per hour. The burn-in boards were } \\
\text { stacked onto a trolley and later pushed to the burn-in area. }\end{array}$ \\
\hline & Chip inspection & $\begin{array}{l}\text { Prolonged sitting, footrest available but no back support (stool). Shoulders } \\
\text { lifted because the table was too high. }\end{array}$ \\
\hline \multicolumn{3}{|l|}{ Parts assembly } \\
\hline & Manual assembly & $\begin{array}{l}\text { Prolonged standing and bending because the table was too low. } \\
\text { Repetitive tasks using mechanical force that put stress on small areas (finger tips). }\end{array}$ \\
\hline & Inspection & Workstation with non-adjustable chairs. \\
\hline
\end{tabular}

standing and working at awkward postures (bending and twisting) were observed. In carrying out inspection, operators had to sit for long hours, some on stools and with their shoulders lifted because the work surfaces were too high, using the naked eye to inspect and tweezers to lift the wafers.

In the semiconductor assembly factories, production line employees were generally involved in four main processes, that is, assembly, inspection, testing and packing. The assembly and testing processes mainly involved operating machines, although some assembly processes, especially the molding process, were semi-automated. Inspection was carried out with microscopes or magnifying lens, while packing was either done manually or with machines.

The first steps in semiconductor assembly consisted of inspection, taping and manually marking defective units with a marker pen. Like the inspection workers in wafer fabrication, these workers were exposed to prolonged sitting in an awkward position. Next, the die attach or mounting process required lifting racks of about $3 \mathrm{~kg}$ for up to six to eight times in an hour to load and unload units into and out of the machines. One worker usually operated several machines which were about $3 \mathrm{~m}$ apart from each other (placed in a row or two parallel rows). The FOL processes were in clean rooms with low temperatures, where workers were required to wear bunny suits to ensure that particles in the air were minimized.

In the MOL work section, the molding, trimming and forming, and soldering processes were observed. At the time of study, only one factory used the older molding machines, whereby operators had to lift metal frames weighing 15 to $20 \mathrm{~kg}$ at and above their waist levels, clean the molding area, place resin (the molding material) into the machines and press buttons. With the new machines that used smaller and lighter metal frames, the workers only loaded and unloaded the basket that together with frames weighed about $4 \mathrm{~kg}$ and they did not have to fill the machines 
with resins.

In the EOL section, operators running the chip testing machines had to climb up three steps in order to load the strips of units onto the carrier. For burn-in testing, the workers had to load and unload the chips manually onto and out of the burn-in boards. This task was carried out with repetitive hand movements and in one factory, it was noted that each operator inserted 1,500 units per hour. The burn-in boards were stacked in a trolley (about $1.5 \mathrm{~m}$ high) which had compartments that could accommodate 40 boards. The heavily loaded trolleys were pushed and pulled to the oven area. In some factories, loading and unloading were automated, nevertheless some units could not be loaded and unloaded automatically because of the varying sizes and types of chips. Final inspection was done with the naked eye or by using a microscope. These operators faced the same ergonomic risk factors as the inspection operators in wafer fabrication, the FOL, and parts assembly, that is, prolonged sitting, awkward posture with lifted shoulders, and repetitive work. Assembly workers, on the other hand, were exposed to prolonged standing, awkward postures, and repetitive work.

\section{Discussion}

\section{Overall prevalence of body pain}

The present study could be directly compared to the survey of 466 women in Tijuana, Mexico, because a similar method (the body map) was used to measure body pain. In the Tijuana study, a prevalence of 59\% was recorded for the 109 women working in electronics maquiladora factories ${ }^{3}$. The present study recorded a much higher prevalence of overall body pain $(81 \%)$, but it should be remembered that the work processes in semiconductor assembly would be different from electronics assembly. The study of two electronics factories in Malaysia, using a modified Nordic questionnaire, recorded overall body pain prevalences $(62 \%$ and $76 \%)$ that were closer to those found in the present study ${ }^{4}$.

Findings in the present study were congruent with the Tijuana study ${ }^{3}$ in that pain prevalences were relatively higher in the upper back, and lower in the hand or wrist, but differ from it in that neck/shoulder pain was more prevalent, and low back pain less so, in the current study. The present study was also different from the Malaysian case study of 61 assembly workers in an electronic component factory which found the highest prevalence of pain in the low back $(30 \%)$, and a lower rate in the upper back $(18 \%)^{5}$. In the present study, low back pain was less prevalent than upper back pain, even among the parts assembly workers $(11.5 \%$ low back pain, 38.5\% upper back pain).

Direct comparisons could not be made with the other studies due to the different methods of outcome measurement ${ }^{2,6,7,9,10)}$. Nevertheless, the study of semiconductor women workers in Malaysia and Singapore, like the present study, had identified back and shoulder pain as a major problem, but unlike the present study, had also identified hand/wrist pain as such ${ }^{10}$.

\section{Wafer fabrication}

For wafer fabrication workers, the major problems were pain in the low back and lower limbs. In wafer preparation, the process of ingot mounting involved lifting heavy ingots $(>30 \mathrm{~kg}$ ), while ingot slicing involved lifting racks containing wafers. Wafer polishing workers lifted racks $(>1 \mathrm{~kg})$ in a repetitive fashion. The wafer polishing process consisted of four steps carried out while standing: mounting the wafer manually onto a plate, lifting the plate (with wafer) onto the polishing surface and operating the polishing machine, de-mounting the wax (if used), and cleaning the wafers in tanks of chemicals. In both wafer preparation and polishing, workers performed tasks while standing for long periods of time, although they sometimes walked short distances in between tasks. The prolonged standing would be an ergonomic risk exposure for lower limb pain. Age could not be ruled out as a confounding factor, as these workers were the oldest and had worked the longest, and although the age-adjusted odds ratios were raised, the measurements were imprecise.

\section{Semiconductor assembly}

The FOL workers had relatively lower prevalences of pain at all body sites, when compared to other workers. Although there were many repetitive lifting tasks among workers in die attach and wire bonding, the loads were lighter, and workers generally had more opportunity to walk in between tasks, as they had to move among the several machines that they operated. Nevertheless, the walking and standing could have contributed to the higher pain prevalences among die attach workers $(58.2 \%)$.

The molding workers in the MOL had the highest prevalences for pain in the neck/shoulders, arms, and upper back. This could be due to the repetitive lifting task that workers needed to perform when operating the molding machines. Although most of the factories had the newer type of machines where lighter frames were used, nevertheless, having to lift even light loads repeatedly could lead to pain. Besides the molding workers, workers in dejunk/ deflash and forming/trimming who had high prevalence of 
upper back pain also performed lifting tasks.

In EOL, the workers in die marking and curing had the highest prevalence for arm pain, which could have been from loading and unloading 1-2 kg trays from ovens. The chip testing workers, who had to climb up and down steps repeatedly to load strips of chips onto carriers for testing, had among the highest prevalences for pain in the hands/ wrists, upper back and lower limbs. Likewise, burn-in workers could have been exposed to risk of hand/wrist pain from loading and unloading chips onto burn-in boards, and to risk of low back pain from bending over to load or unload the boards into and out of the lower shelves in the oven, and from pushing the heavy trolleys. The high neck/shoulder and upper back pain among the chip inspection workers could have resulted from prolonged sitting in awkard postures. It was observed that they were seated with the head and neck in a bent forward position, often on chairs that did not have back support and at tables that were too high. On the other hand, the inspection workers in wafer fabrication and die preparation (FOL) did not have such high prevalences of body pain. This could be because wafer inspection workers used the naked eye to inspect wafers, and therefore did not have to work continuously in a bent forward position, while inspection workers in FOL had intermittent periods of walking about.

\section{Parts assembly}

In one of the factories, the production of diodes was observed to be carried out by operators who were standing and bending their backs to do the task as the level of the table was too low. Another factory had manual assembly work processes, where the operators had to use mechanical force that applied stress on their fingertips. The workers had a very monotonous short cycle of tasks and this made the tasks very repetitive. At the inspection workstation the chairs were non-adjustable and the operator had to work in awkward postures.

Assembly workers in parts assembly had high prevalences of pain in the neck/shoulders, arms and hand/wrists. These workers were exposed to prolonged standing, awkard posture (repetitive bending because the table was too low), and repetitive tasks with the hands and fingers that involved mechanical force at the finger tips. Their relatively higher hand/wrist pain is supported by the studies on hand and wrist pain and carpal tunnel syndrome among electronics assembly workers $^{2,5)}$.

\section{Conclusion}

In this study, the work processes with high prevalences and odds ratios for pain at specific body sites were identified. An attempt was made to understand the ergonomic risk exposures faced by workers at these work processes from qualitative observations at the workplace. Further studies incorporating more detailed observations and measurements need to be carried out so as to be able to make more definitive conclusions.

Overall, EOL workers had high prevalences for pain in all parts of the body. Loading and unloading units into and out of machines seemed to be a major ergonomic risk exposure. Wafer fabrication and MOL molding workers who carried out frequent lifting were also at particularly high risk. In comparison to the other work sections, FOL workers had lower risk, probably because their work involved walking around to operate several machines.

There were two major limitations in the current study. First, the selection of workers was carried out by management personnel, and might not have been strictly random. There could have been a selection bias for healthier workers as well as workers who were more easily released from the production process. If this was so, the findings would be biased toward an underestimation of health problems, and the high prevalences of body pain found would be even greater cause for concern. The second limitation was that objective measurements were not made on postures, movements and work stations. Further studies should incorporate these measurements particularly in the work processes that have been identified to have a high prevalence of body pain.

\section{Acknowledgement}

This study was supported by the Intensification of Research in Priority Areas (IRPA) Program of the Ministry of Science and Technology, Malaysia (IRPA Research Grant No. 0602-05-7011). We wish to thank the Malaysian Department of Occupational Safety and Health for their cooperation and support in carrying out this study.

\section{References}

1) LaDou J, Rohm T (1998) The international electronics industry. Int J Occup Environ Health 4, 1-18.

2) Abbas MF, Faris RH, Harber PI, Mishriky AM, ElShahaly HA, Waheeb YH, Kraus JF (2001) Worksite and personal factors associated with carpal tunnel 
syndrome in an Egyptian electronics assembly factory. Int J Occup Environ Health 7, 31-6.

3) Harlow SD, Cedillo Becerril LA, Scholten JN, Monroy DS, Sánchez RA (1999) The prevalence of musculoskeletal complaints among women in Tijuana, Mexico: Sociodemographic and environmental health. Int J Occup Environ Health 5, 267-75.

4) Tan GLE (1997) Ergonomics in manufacturing industries in Malaysia. Education and Training, Small Industries, Countries in Transition, Theories and Methodologies, Miscellaneous Topics, Vol. 7. In: Proceedings of the 1997 Triennial Congress of the International Ergonomics Association, 160-2, 4.

5) Tan GLE (1994) Ergonomic task analysis in electronics industries: some case studies. In: Ergonomics for Productivity and Safe Work. Proceedings of the $4^{\text {th }}$ South-East Asia Ergonomics Society and Safety and Health at Work Promotion Association International Conference. ed. by Intaranont K, 274-96, South-East Asia Ergonomics Society and Safety and Health at Work Promotion Association, Bangkok.

6) Ho SF, Phoon WH (1997) The significance of aches/ pain among workers in an electronics factory. Med $\mathbf{J}$ Malaysia 52, 134-8.

7) Ho SF, Lee HS (1994) An investigation into complaints of wrist pain and swelling among workers at a factory manufacturing motors for refrigerators. Singapore Med
J 35, 274-6.

8) Schenker MB, Gold EB, Beaumont JJ, Eskenazi B, Hammond SK, Lasley BL, McCurdy SA, Samuels SJ, Saiki CL, Swan SH (1995) Association of spontaneous abortin and other reproductive effects with work in the semiconductor industry. Am J Ind Med 28, 635-911.

9) Pocekay P, McCurdy SA, Samuels SJ, Hammond SK, Schenker MB (1995) A cross-sectional study of musculoskeletal symptoms and risk factors in semiconductor workers. Am J Ind Med 28, 861-71.

10) Lin V (1991) Health, Women's Work, and Industrialization: Semiconductor Workers in Singapore and Malaysia, 174, Garland Publishing, New York \& London.

11) Government of Malaysia (2001) Eighth Malaysia Plan: 2001-2005. Percetakan Nasional Malaysia Bhd, Kuala Lumpur.

12) Malaysia Industrial Development Authority (MIDA) (1998) Industry Brief April 1998. MIDA, Kuala Lumpur.

13) Chee HL, Rampal KG (2004) Work-related musculoskeletal problems among women workers in the semiconductor industry in Peninsular Malaysia. Int J Occup Environ Health 10, 63-71.

14) Kuorinka I, Jonsson B, Kilbom Å, Vinterberg H, Biering-Sørensen F, Andersson G, Jørgensen K (1987) Standardised Nordic questionnaire for the analysis of musculoskeletal symptoms. Appl Ergon 18, 233-7. 